\title{
COMPARISON OF THE SPECIFIC GRAVITY VARIATION OF Swietenia macrophylla, Khaya senegalensis AND Paulownia fortunei
}

P K P Perera and H S Amarasekara

Department of Forestry and Environmental Science

University of Sri Jayewardenepura

Since the existing natural forests have become increasingly subjected to conservation pressure, forest plantations have been recognized as an alternative to meet the future demand for sawn timber. A major drawback for the efficient utilization and promotion of new species such as Khaya senegalensis and Paulownia fortunei as well as much familiar Swietwnia macrophylla is the lack of information regarding their wood properties grown under local conditions. The present work was designed to determine specific gravity of each species, investigate the variation of specific gravity within the species and to determine the effect of growth rate on specific gravity.

Specific gravity variations were studied in 79 year old Swietwnia macrophylla, 49 year old Khaya senegalensis and 16 year old. and Paulownia fortunei trees. Three trees were selected from each species and pith to bark variation was investigated in sample disks removed at breast height, $50 \%$ and $80 \%$ heights of the bole length. Radial variations were studied at percentage distances from the pith.

The mean numerical specific gravity values obtained for Swietwnia macrophylla, Khaya senegalensis and and Paulownia fortunei were $0.511,0.617$ and 0.317 respectively and these values suggest that the values are comparable to those earlier published data for other countries. The results of this study indicate that general pattern of radial variation of specific gravity in both Swietwnia macrophylla and Khaya senegalensis was to remain uniform from pith to bark. This pattern was evident at all the height levels. In Paulownia fortune, the radial trend was to show a gradual increase from pith to bark at all the height level i. The axial trend of Swiefwnia macrophylla was higher specific gravity at the base, drops to a minimum at mid height and increase again to a maximum at merchantable top. Khaya senegalensis showed a gradual increase from base to top. The axial variation was not significant in both these species. and Paulownia fortunei showed a significant reduction of specific gravity from base to top.

To investigate the effect of growth rate on specific gravity, sample disks were extracted at breast height and ring width and whole ring specific gravity were measured based on the growth rings identified from pith to bark. Results indicated that no substantial and definite relationship appears to exist between whole ring specific gravity and ring width representing the growth rate in Swietwnia macrophylla, Khaya senegalensis (diffuseporous) and and Paulownia fortunei (ring-porous).

Proceedings of the Ninth Annual Forestry and Environment Symposium 2003 of the Department of Forestry and Environmental Science, University of Sri Jayewardenepura. Sri Lanka 